Research Article

\title{
Coordination Strategy of the Supply Chain with Consumer Preferences under the "Presale and Spot-Sale" Mode
}

\author{
Xiaogang Cao, ${ }^{1,2}$ Hui $W u,{ }^{3}$ Kebing Chen $\mathbb{D}^{4},{ }^{4}$ and Hui Wen ${ }^{5}{ }^{5}$ \\ ${ }^{1}$ School of Management, Wuhan Textile University, Wuhan 430073, China \\ ${ }^{2}$ The Key Research Base of Humanities and Social Sciences, Colleges and Universities, \\ Hubei Province-Enterprise Decision Support Research Center, Wuhan 430073, China \\ ${ }^{3}$ School of Management, Guangdong University of Science and Technology, Dongguan 523083, China \\ ${ }^{4}$ College of Economics and Management, Nanjing University of Aeronautics and Astronautics, Nanjing 210016, China \\ ${ }^{5}$ School of Science, Hubei University of Technology, Wuhan 430068, China
}

Correspondence should be addressed to Hui Wen; wen_hui@126.com

Received 21 October 2019; Revised 2 March 2020; Accepted 17 March 2020; Published 6 May 2020

Academic Editor: Harish Garg

Copyright $(92020$ Xiaogang Cao et al. This is an open access article distributed under the Creative Commons Attribution License, which permits unrestricted use, distribution, and reproduction in any medium, provided the original work is properly cited.

In recent years, the market economy has been booming, and the demand of consumers has begun to become diversified. Consumers' preferences for products, the sensitivity of product prices, and other factors can often affect the market demand and also make enterprises realize the importance of consumer preferences. The decision-making model of the supply chain with consumer preference composed of a retailer and a third-party presale platform is established, and we analyze the implementation of a single presale model, a single spot-sale model, and decision-making models under the "presale and sale" mode. The equilibrium strategy of centralized decision and decentralized decision under the mode of "presale and sale" is compared, and the influence of the proportion of informed consumers and the exogenous variables of cross-period discount on supply chain decision is further analyzed. The coordination strategy of the decentralized decision supply chain under the mode of "presale and sale" is put forward, and the coordinated operation among supply chain members is realized. The results show that compared with other sales models, the "presale and spot-sale" model is more beneficial to the profit of the supply chain.

\section{Introduction}

With the rapid development of the Internet, various emerging sales models are emerging, especially in recent years, the presale mode is more and more popular with the merchants and consumers. Presale refers to a sales mode in which the merchant provides a commodity or service scheme, aggregates consumer orders in advance through the presale platform, and provides goods and/or services to consumers in accordance with the prior agreement after a certain period of time. The presale is usually to pay the deposit first, pay the final payment after the official sale, and then ship the goods. Products are often sold at a discount in the presale period and at full price in the spot period $[1,2]$. Consumers determine whether to buy or when to buy by observing the price difference between the two periods.
The "presale and spot-sale" model is often adopted by the retailers when the supply of goods is lower than the demand. Retailers can step up their stocking during the presale period to meet the demand for the presale period to avoid the loss of potential customers. For example, when Xiaomi company launches new products, it is often highly sought after by consumers, resulting in a situation of short supply. On February 20, 2019, the Xiaomi 9 mobile phone was released. At the beginning of the new product launch, the supply was extremely scarce, and Xiaomi took a weekly limited purchase; On March 22, Xiaomi company made a full presale of Xiaomi 9 mobile phone and set the presale period to 3 weeks (http://tech.ifeng.com/a/20190322/45585259_0.shtml).

Xiaomi company adopts the same price strategy of presale price, and spot-sale price $([2,3]$ also adopt this pricing strategy in their research), and other scholars also adopt 
differentiated price strategy in their research: for example, the presale price is higher than the on-the-spot price [4], and the presale price is lower than the on-the-spot price $[5,6]$. It fully demonstrates that, in the context of short supply, when the product supply capacity reaches a certain level, adopting the form of "presale and spot-sale" is an effective sales method.

A large number of cases show that consumers' preferences will affect the actual sales volume, so consumer preference is also the focus of many enterprises. For example, when Huawei chooses the presale platform in Switzerland, it takes the consumer preference into consideration and chooses Digitec, the largest online retailer in Switzerland, as its partner (https:// www.gsmarena.com/huawei_mate_30_pro_goes_up_for_ presale_at_major_swiss_retailer-news-40438.php). In addition, the cooperation among supply chain members cannot be ignored.

A large number of studies show that cooperation in the supply chain can be carried out in the form of contracts and can obtain additional benefits or reduce certain costs, such as Zhang et al. [7]; Johari et al. [8]; and Hosseini-Motlagh et al. [9]. In the dual-channel supply chain, the coordinated measures are often that the leaders of the positive and negative supply chain (not the same) put forward their own preferential prices to reach a lower retail price so as to increase the demand and realize the increase of the profits of the supply chain. The coordination strategy can make the decision efficiency of supply chain approach or reach the ideal state of centralized decision-making so that the theory can be combined with practice. So, it is necessary to study the coordination strategy.

Based on the consideration of consumer preferences, this paper studies the influence of different sales modes on the supply chain. This paper will answer the following two questions:

(1) In case of insufficient supply to meet the demand, how will the proportion of consumers' knowledge about presale and the cross-period discount affect the decision-making of the supply chain?

(2) How to coordinate the supply chain so that decentralized decision-making can achieve the same profits and retail price as centralized decisionmaking?

The novelties of this paper are as follows:

(1) In the above literature studies, the majority of scholars often studies the subjective preference of consumers, without considering the objective problem that consumers are not aware of the presale. We classify the consumers according to whether they are informed or not and consider their preferences in our paper.

(2) We build four basic models and a coordination model. In the above models, we study and compare the decisions of the retailer and the thirdparty platform, taking into account the possible strategies adopted by members of the supply chain.
The remainder of the paper is as follows. In Section 2, we make a brief literature review and put forward the main contribution of the paper. Section 3 describes the model and basic assumptions. We present five decision models of the supply chain in Section 4. Section 5 presents a numerical analysis, and we conclude this paper in Section 6.

\section{Literature Review}

There are four streams of literature that are closely related to our work. (1) The optimal pricing decisions of the supply chain; (2) consumer preferences; (3) presale and spot-sale; and (4) supply chain coordination.

2.1. The Optimal Pricing Decisions of the Supply Chain. In the research of supply chain pricing, Arya et al. [10] analyzed the impact of dual-channel operations on remanufacturing decisions. Ferguson and Toktay [11] analyzed the competition between new and remanufactured products produced by the monopoly manufacturer, as well as the external remanufacturing competition. José et al. [12] studied the impact of interactive supply chains between freight forwarders on public policy initiatives based on pricing and incentives. Jadidi et al. [4] studied the dual price strategy of the newsvendor product supply chain considering the influence of time and price sensitivity on demand. Wang et al. [13] studied how the pricing strategy of the supply chain affects profits and social welfare in the case of carbon emission constraints. Sarkar et al. [14] built a supply chain of retailers and two manufacturers that produce complementary products and studied pricing decisions in the supply chain. Batarfi et al. [15] studied the influence of learning and forgetting on the supplier's production process in a two-level dual-channel supply chain and analyzed the influence of various factors on pricing decisions. RanjanVoigt and Jha [16] also conducted similar research, focusing more on the cooperation between manufacturer and retailer in the supply chain. The above literature has a detailed study on the pricing strategy of the supply chain. This paper draws on the research methods of the above literature and uses game theory and pricing order to solve the pricing strategy of the supply chain. The above literature studies the impact of various factors on supply chain pricing, but in view of the presale under the new situation, the above literature cannot be involved. This paper innovatively studies the impact of presale on supply chain pricing strategy and has a certain degree of innovation in the research issues.

2.2. Consumer Preferences. Many scholars have studied consumer preferences in supply chains. Conrad [17] established a duopoly decision model based on consumers' willingness to pay for product environmental attributes and analyzed the impact of consumer environmental awareness on member decision-making in the supply chain. Ferrer and Swaminathan [18] hypothesized that consumers have heterogeneous preferences for new and remanufactured products and studied the optimal yield and pricing decisions for multiple remanufacturing systems. 
Chitra [19] pointed out that companies should adopt a more environmentally friendly market strategy to capture consumers' preference for green products, and Atasu et al. [20] showed that green consumers like corporate remanufacturing and are willing to buy remanufactured products to increase corporate profits. Guide and Li [21] and other researchers pointed out that consumers' willingness to pay for remanufactured products and new products is different, and this difference will have a greater impact on manufacturers' decision-making. Li and Zhang [22] studied the influence of demand information on retailer's decision-making and found that accurate demand information may reduce the shortage of the product. Gan et al. [23] considered consumer price preferences for new products and remanufactured products and studied dualchannel closed-loop supply chain pricing and coordination decisions. Abbey et al. [24] analyzed the consumer's risk perception of remanufactured product quality on product pricing and found that consumer quality perception plays an important role in product pricing. Genc et al. [25] have studied several consumers' return behaviors for the used products which are based on the product prices and rebates. In the research of consumer preferences, many alternatives are often provided for consumers to choose. The research in the above literature provides consumers with a variety of choices, such as new products and remanufactured products and different sales channels, but seldom from the different periods of presale and spot-sale. This paper studies consumers' preferences from purchasing channels and retail prices and divides consumers into two groups by whether they know the presale information or not, which is different from the above literature studies.

2.3. Presale and Spot-Sale. Many scholars have studied presale in supply chains. Guo and Villas-Boas [3] studied the influence of strategic consumers' choice of presale decision on enterprise pricing strategy and also considered the effect of product hoarding. Cho and Tang [26] studied three sales strategies of a manufacturer who produces and sells seasonal products under uncertain supply and demand conditions. On the basis of consumer preference, Lim and Tang [5] divided consumers into multiple types and examined the impact of consumer's expected valuation on seller behavior. The research shows that, in a downward market, the expected valuation decreases over time, and the seller prefers to sell in advance. Prasad et al. [6] found that presale strategy is not always optimal but depends on market factors and consumer preferences such as market potential and uncertainty or valuation, risk aversion, and heterogeneity. Mei et al. [2], in their research, assumed that the manufacturer did not publish the on-the-spot price in advance and studied the mechanism of the presale price and the spot-sale price on the supply chain. He et al. [1] studied the impact of the entry of online grocery stores on physical stores. In the above literature, presale is studied and modeled from the perspective of consumer preference, which gives some inspiration to this paper. However, the above literature has not studied the impact of external conditions; this paper studies the impact of the proportion of informed consumers and the cross-period discount on supply chain decision-making.

2.4. Supply Chain Coordination. Dekker et al. [27] used qualitative analysis to study the main factors of closed-loop supply chain coordination and pointed out that pricing decision plays an important role in reverse channel coordination. Savaskan and Wassenhove [28] constructed a pricing decision model for a closed-loop supply chain consisting of an independent manufacturer and multiple retailers with competitive relationships and designed a contract to coordinate the closed-loop supply chain. Zhang et al. [7] constructed a two-echelon supply chain model with double-sided disruptions, proposed two coordination models AQDP and CLPP, and explained the specific situation that this coordination model is suitable for application. In the sustainable closed-loop supply chain, Johari and Hosseini-Motlagh [8] proposed and verified the promotion effect of two-way two-part tariff contract on collection rate, consumer surplus, social welfare, and profits of all CLSC members. Hosseini-Motlagh et al. [9] proposed two-part tariff contract, which can improve the profits of the reverse supply chain and its members and improved the environment. The above literature provides us with ideas and theoretical basis, and we adopt the coordinated thinking of Savaskan et al. [29].

2.5. Research Gaps and Contributions. All the above works do not consider the interactions among presale, spot-sale, and consumer preferences, which is the focus of our paper. The main contributions of this paper are as follows: firstly, we make up a consumption mix of presale and spot-sale for consumers to choose. The influence of consumers' preferences on supply chain decision-making under the situation of spot and presale is analyzed. Secondly, the existed literature studies have not considered the coordination problem of the supply chain under the presale and sale modes. In this paper, a two-part tariff contract is designed to coordinate the decentralized decision supply chain under the mode of "presale and sale," and the coordinated operation among supply chain members is realized.

\section{Model Description and Basic Assumptions}

Consider that a supply chain system consists of a monopoly retailer (she) and an optional third-party presale platform (he). The retailer provides consumers with the same product through the "presale" or "spot-sale" model. The operation mode of "presale and spot-sale" is as follows: first, presale information including presale price and spot-sale price is published on the third-party presale platform, and informed consumers will make purchase or wait decisions based on the disclosed information. For the sake of simplicity, consumers who know presale information are called informed consumers, and consumers who do not know presale information are called uninformed consumers in this paper. Then, it is the spot-sale stage. The retailer delivers goods to the consumers who buy the products in the presale stage and 
starts to sell the products in large scale. At this time, the uninformed consumers and the informed consumers who do not buy the products in the presale stage make the decision whether to buy or not. The decision sequence of the retailer and consumers is shown in Figure 1.

The following assumptions are made to establish the models.

Assumption 1. Suppose that the consumers in the whole market are normalized to 1 , in which the proportion of informed consumers is $\lambda$, and $0<\lambda<1$. So, the proportion of uninformed consumers is $1-\lambda$.

Assumption 2. Assuming that informed consumers are more sensitive to the purchase opportunity and are keen to pursue "new product launch," they will obtain psychological satisfaction when they purchase products in the presale period. On the contrary, if you give up the purchase in the presale period, you will lose this part of satisfaction. In this paper, it is called the cross-period discount, which is recorded as $\eta, 0<\eta<1$. [30] makes a similar assumption and calls it "per-period discount factor." It is assumed that $\eta$ is an exogenous variable related to the properties of the product.

Assumption 3. Assuming that the market demand of the product is composed of a group of heterogeneous consumers, the reserved price of a consumer is $v$, which reflects the degree of consumer preference for the product, and $v$ is evenly distributed on $[0,1]$. Every consumer buys only one item at most. For example, if a consumer purchases a product e-ticket in the presale period, he will not buy the product again in the spot-sale period.

Informed consumers who have purchasing behavior in presale are represented by $a$. The spot-sale period begins immediately after the end of the presale period. Informed consumers who do not buy in the presale stage enter the market, choose to buy products or withdraw from the market. Informed consumers who abandon purchase in the presale period but purchase in the spot-sale period are represented by $b$. Informed consumers and uninformed consumers who have purchasing behavior in the spot-sale stage are represented by c. Then, Assumption 4 is put forward.

Assumption 4. The retailer prices presale and spot-sale products differently, and the retail prices are denoted by $p_{1}$ and $p_{2}$, respectively. We record consumer utility as $u$.

After the presale information is disclosed, informed consumers will evaluate the consumer surplus obtained by purchasing products in the presale period and in the spotsale period. The consumer surplus obtained in the presale period is the difference between the reservation price and the presale price, $u_{a}=v-p_{1}$; if consumers choose to buy in the spot-sale period, they will lose part of satisfaction, that is to say, there will be a cross-period discount, so the consumer surplus of the products purchased in the spot-sale period is $u_{b}=\left(v-p_{2}\right)(1-\eta)$; and the uninformed consumers have missed the presale period, so there will be no cross-period discount; so the consumer surplus of the products purchased in the spot-sale period is $u_{c}=\left(v-p_{2}\right)$.

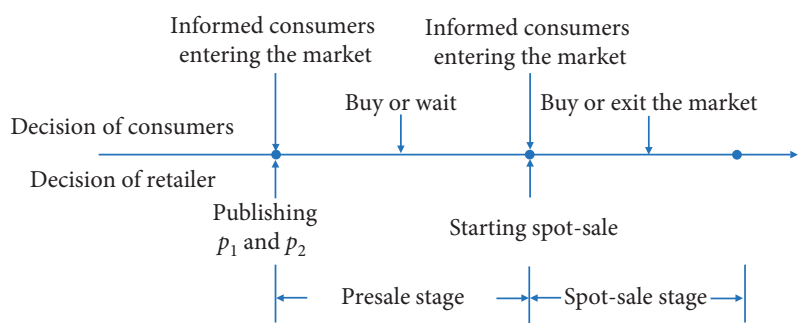

Figure 1: Decision order in the "presale and spot-sale" model.

Assumption 5. If the retailer carries out presale on the thirdparty presale platform, the retailer must pay a certain commission to the third-party presale platform for each presale order completed. Here, the unit commission is recorded as $f$, and $f$ is the decision variable of the thirdparty presale platform.

According to the above assumptions, the main symbols in this paper are shown in Table 1.

Assumption 6. Suppose that all the consumers in the market are strategic consumers, they will buy when the utility of consumers is greater than 0 and when the utility of consumers is the greatest.

According to the consumer utility theory, Proposition 1 can be obtained. The proof process is shown in Appendix.

\section{Proposition 1}

(i) Informed consumers whose reservation price is within the range of $\left[\left(p_{1}-p_{2}+\eta p_{2}\right) / \eta, 1\right]$ will buy products in advance

(ii) Informed consumers whose reservation price is within the range of $\left[p_{2},\left(p_{1}-p_{2}+\eta p_{2}\right) / \eta\right)$ will buy products in the spot-sale period

(iii) Uninformed consumers will only buy products in the spot-sale period, and the reservation price will choose to buy products in the range of $\left[p_{2}, 1\right]$

Proposition 1 shows that the decision-making of informed consumers is influenced by the reservation price, presale price, spot-sale price, and the cross-period discount. For informed consumers, the presale price and spot price are uncontrollable. Therefore, the reservation price of informed consumers has two thresholds $p_{2}$ and $\left(p_{1}-p_{2}+\eta p_{2}\right) / \eta$. When the reservation price is lower than $p_{2}$, the consumer utility is negative, and the consumer will not buy the product and leave the market. When the reservation price is higher than $p_{2},\left(p_{1}-p_{2}+\eta p_{2}\right) / \eta$ will be the threshold for informed consumers to choose to buy in the presale or spotsale period, and the presale price should be higher than the spot-sale price.

According to Proposition 1, the purchase volume $q_{a}$ of the informed consumer in the presale period, the purchase volume $q_{b}$ of the informed consumer in the spot-sale period, and the purchase volume $q_{c}$ of the uninformed consumer can be obtained: 
TABLE 1: The description of the symbols.

\begin{tabular}{|c|c|c|}
\hline Symbol & & Description \\
\hline \multirow{6}{*}{ Subscript } & $r$ & Retailer \\
\hline & $p$ & Third party presale platform \\
\hline & $T$ & Overall supply chain \\
\hline & $a$ & Informed consumers who buy products during the presale period \\
\hline & $b$ & Informed consumers who buy products during the spot-sale period \\
\hline & $c$ & Uninformed consumers who buy products during the spot-sale period \\
\hline \multirow{5}{*}{ Superscript } & $N$ & Spot-sale model \\
\hline & $R$ & Presale model \\
\hline & $D$ & Decentralized decision-making model under the "presale and spot-sale" mode \\
\hline & $C$ & Centralized decision-making model under the "presale and spot-sale" mode \\
\hline & $\mathrm{CM}$ & Supply chain coordination strategy \\
\hline Decision variables & $\begin{array}{l}p_{i} \\
f\end{array}$ & $\begin{array}{c}i \in\{1,2\} \text { indicates the price of the product for the presale period and the spot period, respectively } \\
\text { Unit product commission charged by the third-party presale platform }\end{array}$ \\
\hline \multirow{4}{*}{ General variables } & $q_{i}$ & $\begin{array}{c}i \in\{a, b, c\} \text {, the supply chain can meet the demand of class } i \text { consumers, that is, the actual purchases of class } i \\
\text { consumers }\end{array}$ \\
\hline & $u_{i}$ & $i \in\{a, b, c\}$, representing consumer utility for consumers \\
\hline & $v$ & Consumer reservation price \\
\hline & $\Pi_{i}$ & $i \in\{r, p\}$ representing the profit of the retailer and third-party presale platforms \\
\hline \multirow{2}{*}{$\begin{array}{l}\text { Constant } \\
\text { parameters }\end{array}$} & $\lambda$ & Proportion of informed consumers in the market \\
\hline & $\eta$ & Cross-period discount \\
\hline
\end{tabular}

$$
\begin{aligned}
& q_{a}=\int_{\left(p_{1}-p_{2}+\eta p_{2}\right) / \eta}^{1} \mathrm{~d} v=\left(1-\frac{p_{1}-p_{2}+\eta p_{2}}{\eta}\right) \lambda, \\
& q_{b}=\int_{p_{2}}^{\left(p_{1}-p_{2}+\eta p_{2}\right) / \eta} \mathrm{d} v=\left(\frac{p_{1}-p_{2}}{\eta}\right) \lambda, \\
& q_{c}=(1-\lambda) \int_{p_{2}}^{1} \mathrm{~d} v=\left(1-p_{2}\right)(1-\lambda) .
\end{aligned}
$$

According to the above, sales volume in different periods is affected by presale retail price, spot retail price, the proportion of informed consumers, and the cross-period discount. The sales volume $q_{a}$ of the presale period is positively correlated with the proportion of informed consumers; the sales volume $q_{b}$ of informed consumers is positively correlated with the proportion of informed consumers in the spotsale period and negatively correlated with the cross-period discount in the spot-sale period; and the sales volume of uninformed consumers is negatively correlated with the proportion of informed consumers, the cross-period discount in the spot-sale period, and the spot-sale price.

\section{Decision Models of the Supply Chain}

The following four decision models are considered: (1) retailer's spot-sale model (model $N$ ), where the retailer only sells spot-sale without preselling, while the third-party presale platform does not participate in the supply chain. (2) Retailer presale model (model $R$ ), where the retailer only presells and abandons the spot link, and the supply chain composed of the retailer and the third-party presale platform makes joint decision. (3) Decentralized decision-making (model $D$ ) under the mode of "presale and spot-sale." The retailer and thirdparty presale platforms make decisions in order to maximize their profits. (4) Centralized decision-making (model C) under the mode of "presale and spot-sale." The retailer and the third-party platform form a decision-making body and take the optimal profit of the alliance as the goal to make decisions.

Symbolic representation: in this paper, the optimal solution is denoted as *, and the related results of different models are denoted as ${ }^{A}, A \in\{N, R, D, C\}$.

4.1. Single Spot-Sale Model (Model N). In this model, the retailer only carries on the spot-sale but does not carry on the presale, and the third-party presale platform does not participate in the supply chain. The retailer's profit comes from the sales revenue at the stage of the spot-sale period. The decision variable is the product price of spot-sale $p_{2}$. Consumers who retain the price higher than the product price $p_{2}$ will buy the product. It is easy to know that the sales volume $q_{c}^{N}=\left(1-p_{2}\right)$ at this time, and the retailer's profit function is as follows:

$$
\max \prod_{r}^{N}\left(p_{2}\right)=q_{c}^{N} p_{2} \text {. }
$$

By substituting $q_{c}^{N}=\left(1-p_{2}\right)$ into (4), we can get $\prod_{r}^{N}\left(p_{2}\right)=\left(1-p_{2}\right) p_{2}$, and intelligible (4) has a maximum value. According to $\left(\partial \Pi_{r}^{N} / \partial p_{2}\right)=0$, we can get the optimal decision of the retailer and the optimal profit of the retailer in the spot-sale model, as shown in Proposition 2.

Proposition 2. In the spot-sale model, the retailer can get the maximum profit when the retail price is $p_{2}^{N *}=1 / 2$, and the optimal profit is $\Pi_{r}^{N *}=1 / 4$.

Proposition 2 shows that, in the retailer's spot-sale model, the retailer will set a fixed retail price, which has nothing to do with the cross-period discount and proportion of informed consumers; however, the retailer's optimal profit is negatively related to the cross-period discount because in this case, consumers only have to buy or give up options, and the system lacks flexibility. 
4.2. Single Presale Model (Model R). In this model, the retailer only carries on the presale process but does not carry on the spot-sale. The third-party presale platform participates in the supply chain as the leader of the supply chain. The retailer and the third-party presale platform make decisions to obtain their maximum profits. In this model, informed consumers make decisions in the presale period, while consumers who do not buy products in the presale period exit the market directly. The retailer's profit comes from the sales revenue in the presale stage. The decision variable is the product price $p_{1}$ in the presale period. Informed consumers whose reservation price is higher than the product price $p_{1}$ will buy the product. It is easy to know that the sales volume $q_{a}^{R}=\left(1-p_{1}\right) \lambda$ at this time. Then, the profit function of the retailer and the third-party presale platform is

$$
\begin{aligned}
& \prod_{r}^{R}\left(p_{1}\right)=q_{a}^{R}\left(p_{1}-f\right), \\
& \prod_{p}^{R}(f)=q_{a}^{R} f .
\end{aligned}
$$

Proposition 3. In the retailer presale model (model $R$ ), when the retailer's retail price is $p_{1}^{R *}=3 / 4$ and the unit platform commission charged by the third-party presale platform is $f_{1}^{R *}=1 / 2$, both the retailer and the third-party presale platform can obtain their maximum profits.

The optimal profits of the retailer and the third-party presale platform are $\Pi_{r}^{R *}=\lambda / 16$ and $\Pi_{p}^{R *}=\lambda / 8$, respectively.

Proposition 3 shows that, in the presale model, the profit of the retailer and third-party presale platforms is positively correlated with the proportion of informed consumers in the market. This is because the profit comes from the sales of informed consumers, and the proportion of informed consumers is directly related to the profit of the retailer and third-party presale platforms. Comparing with Proposition 2 and Proposition 3 , we can see that $p_{1}^{R *}>p_{2}^{N *}, \Pi_{r}^{R *}+\Pi_{p}^{R *}<\Pi_{r}^{N *}$. Therefore, compared with model $N$, model $R$ has neither economic nor social benefits.

4.3. Decentralized Decision-Making under the "Presale and Spot-Sale" Mode (Model D). In the decentralized decisionmaking model, the profit of the retailer comes from the sales revenue of the presale period and spot-sale period, and the revenue of the third-party presale platform comes from the commission paid by the retailer. Therefore, the profit functions of the retailer and the third-party presale platform in the decentralized model are as follows:

$$
\begin{aligned}
\prod_{r}^{S}\left(p_{1}, p_{2}\right) & =q_{a}\left(p_{1}-f\right)+\left(q_{b}+q_{c}\right) p_{2}, \\
\prod_{p}^{S}(f) & =q_{a} f .
\end{aligned}
$$

The order of decision-making in this supply chain is the third-party presale platform first announces the commission of each unit product. According to the commission determined by the presale platform, the retailer will make decisions on the presale price and the spot-sale price and evaluate the expected profit to decide whether to adopt the "presale and spot-sale" model. If the profit of the "presale and spot-sale" model is larger than that of the current model, the retailer will adopt the "presale and spot-sale" model; otherwise, the retailer will not carry out presale. The game process conforms to Stackelberg game.

Proposition 4. The retailer will adopt the model of "presale and spot-sale," and in the decentralized decision-making of "presale and spot-sale," the optimal decision-making of the retailer's expected price and spot price is $p_{1}^{D *}=\left(-8+3 \eta(-2+\lambda)+\eta^{2} \lambda\right) /(4(-4+\eta \lambda)) \quad$ and $p_{2}^{D *}=(8-3 \eta \lambda) /(16-4 \eta \lambda)$, respectively. The optimal commission per unit charged by the presale platform is $f^{D *}=\eta / 4$.

Proposition 4 shows that the presale price is higher than the spot-sale price in the decentralized decision-making model, that is, $p_{1}^{D *}-p_{2}^{D *}=(\eta(6-\eta \lambda) / 4(4-\eta \lambda))>0$. This is because under the hypothesis of this paper, when the spotsale price is lower than the presale price, it can stimulate the desire of consumers who are more sensitive to the price to buy. The unit commission charged by the third-party presale platform is positively correlated with the cross-period discount.

4.4. Centralized Decision-Making under the "Presale and SpotSale" Model (Model C). In the centralized decision-making model, retailer and third-party presale platform cooperate closely, and the information between them is fully shared, and the goal is to achieve the maximum revenue of the supply chain. The profit of the supply chain comes from sales revenue of the presale period and spot-sale period, so the profit function of the centralized model supply chain as a whole is as follows:

$$
\prod_{T}^{C}\left(p_{1}, p_{2}\right)=q_{a} p_{1}+\left(q_{b}+q_{c}\right) p_{2} \text {. }
$$

The centralized decision-making is similar to that in the decentralized model. The retailer and the third-party presale platform need to evaluate the overall profit of the supply chain. When the overall profit of the supply chain is greater than that of the retailer at the spot-sale model ( $N$ model), the retailer and third-party presale platforms will carry out the presale mode.

Proposition 5. In the centralized decision-making under the "presale and spot-sale" mode, the equilibrium presale price and spot-sale price decisions of the supply chain are $p_{1}^{C *}=1+((2-$ $\eta) /(-4+\eta \lambda))$ and $p_{2}^{C *}=1+(2 /(-4+\eta \lambda))$, respectively.

The equilibrium solutions and profits of the above four models are shown in Table 2 (the blanks are no such items).

Proposition 6. In different decision models, the presale price of the product satisfies the following relationship: when $3-$ $\sqrt{5}<\eta<1$ or $(2 / 3)<\eta<3-\sqrt{5}$ and $0<\lambda<\left(2(3 \eta-2) / \eta^{2}\right)$, 
TABLE 2: Supply chain equilibrium results and profits in different models.

\begin{tabular}{lcccc}
\hline Results & Model $N$ & Model $R$ & Model $D$ & Model $C$ \\
\hline$p_{1}^{*}$ & & $3 / 4$ & $\left(-8+3 \eta(-2+\lambda)+\eta^{2} \lambda\right) /(4(-4+\eta \lambda))$ & $1+((2-\eta) /(-4+\eta \lambda))$ \\
$p_{2}^{*}$ & $1 / 2$ & & $(8-3 \eta \lambda) /(16-4 \eta \lambda)$ & $1+(2 /(-4+\eta \lambda))$ \\
$f^{*}$ & & $1 / 2$ & $\eta / 4$ & $\lambda /(4-\eta \lambda)$ \\
$q_{a}^{*}$ & $\lambda / 4$ & $\lambda /(8-2 \eta \lambda)$ & $\lambda /(4-\eta \lambda)$ \\
$q_{b}^{*}$ & & & $-((-1+\lambda)(-8+\eta \lambda) / 4(-4+\eta \lambda)$ & $2(-1+\lambda) /-4+\eta \lambda$ \\
$q_{c}^{*}$ & $1 / 2$ & $\lambda / 16$ & $(16-3 \eta \lambda) /(64-16 \eta \lambda)$ & $1 /(4-\eta \lambda)$ \\
$\prod_{r}^{*}$ & $1 / 4$ & $\lambda / 8$ & $\eta \lambda /(32-8 \eta \lambda)$ & \\
$\prod_{p}^{*}$ & & & & \\
\hline
\end{tabular}

there are $p_{1}^{C *}<p_{1}^{R *}<p_{1}^{D *}$; when $0<\eta<\quad(2 / 3)$ or $(2 / 3)<\eta<3-\sqrt{5}$ and $\left(2(3 \eta-2) / \eta^{2}\right)<\lambda<1$, there are $p_{1}^{C *}<p_{1}^{D *}<p_{1}^{R *}$.

The spot-sale prices satisfy $p_{2}^{C *}<p_{2}^{D *}<p_{1}^{N *}$.

Proposition 6 comparatively analyzes the relationship between the equilibrium presale price satisfaction of different decision models. The presale price of the centralized decision model (model $C$ ) is always smaller than the decentralized decision model (model $D$ ) and the presale model (model $R$ ); it overcomes the double marginal effect in the model $D$. The double marginal effect in decentralized decision-making allows for lower prices. Hereinafter, $3-\sqrt{5}<\eta<1$ or $(2 / 3)<\eta<3-$ $\sqrt{5}$ and $\left(2(3 \eta-2) / \eta^{2}\right)<\lambda<1$ is regarded as a case where cross-period discount is high; $0<\eta<(2 / 3)$ or $(2 / 3)<\eta<3-$ $\sqrt{5}$ and $0<\lambda<\left(2(3 \eta-2) / \eta^{2}\right)$ is regarded as a case where cross-period discount is low. When the cross-period discount is high, the presale price in the decentralized decision model is higher than the presale model (model $R$ ); when the crossperiod discount is low, the presale price in the decentralized decision model is lower than the presale model (model $R$ ).

Proposition 7. For the above decision-making models, the sales volume of products during the presale period satisfies $q_{a}^{C *}>q_{a}^{R *}>q_{a}^{D *}$. We record the sales volume in the spot-sale period as $q_{2}$, and $q_{2}=q_{b}+q_{c} . q_{2}$ in the three cases is related as follows: $q_{2}^{N *}>q_{2}^{D *}>q_{2}^{C *}$.

Proposition 7 analyzes the sales volume of products with different sales cycles in different decision models. The presale volume of model $C$ is always the highest followed by model $R$, and model $D$ is the lowest. This is because the presale price in model $C$ is the lowest (Proposition 6), which is bound to stimulate the sales volume during the presale period more than other models. The sales volume of the spot-sale period includes the sales volume of two consumer groups, which will be affected by the supply chain decision-making model.

Proposition 8. For the retailer, the profits are related as and $\Pi_{T}^{C *}>\Pi_{r}^{C *}>\Pi_{r}^{D *}>\Pi_{r}^{R *}$; for the third-party platform, the profits are related as $\Pi_{T}^{C *}>\Pi_{p}^{R *}>\Pi_{p}^{D *}$ and $\Pi_{T}^{C *}>\Pi_{p}^{R *}+\Pi_{r}^{R *}$.

Proposition 8 describes the profit comparison between the retailer and the third-party presale platform under different models. It can be seen from the comparison that the retailer has the subjective initiative to invest in the presale and spot-sale activity because the profit in the presale and spot-sale model is greater than that in the single presale model and the single spot- sale model. But, the decentralized spot-sale model cannot attract the third-party presale platform because a single presale model can obtain more profits. However, we can see that both retailer and third-party platform can obtain excess profits in presale and spot-sale decision-making under the centralized decision-making. However, it is necessary to put forward a coordinated decision so that both sides can accept it, which is discussed in Section 4.5.

Proposition 9. The total profit of the supply chain in the three cases is related as follows: $\Pi_{T}^{C *}>\Pi_{T}^{D *}>\Pi_{T}^{N *}>\Pi_{T}^{R *}$.

Proposition 9 compares the optimal total profit of the supply chain in different models. Compared with the spot-sale model, using the "presale and spot-sale" model will be conducive to the improvement of the total profit of the supply chain. On the one hand, because the presale price of the "presale and spot-sale" model is higher than the spot price, the supply chain can obtain excessive profits; on the other hand, the "presale and spot-sale" model can promote market demand. The total profit of centralized decision-making is always higher than that of decentralized decision-making. Although the presale price and spot price of the centralized decisionmaking model are lower than those of decentralized decisionmaking, the higher sales volume of the centralized decisionmaking model is enough to make up for the gap in retail price and make centralized decision-making obtain higher profits.

4.5. Supply Chain Coordination Strategy (CM Model). Centralized decision-making can make the supply chain obtain the best profit, social effect, and higher environmental adaptability. But, in reality, companies in the supply chain are often more beneficial to themselves when making decisions, and at the same time, it is unavoidable to harm the interests of other companies, so the above situation is more in line with the decentralized decision model. It is difficult to achieve the effect of the centralized decision mode. Two-part tariff contracts are designed to coordinate the supply chain. The third-party presale platform determines a lower platform commission $f^{\mathrm{CM}}$, which encourages the retailer to sell at lower presale price and spot price to maximize the overall profit and social benefit of the supply chain. At the same time, the retailer needs to pay a fixed fee $F^{\mathrm{CM}}$ to the thirdparty presale platform to compensate. Third-party presale platform reduces the loss of platform commission. Then, the decision-making problems of the third-party presale platform and the retailer can be expressed as follows: 


$$
\begin{aligned}
& \prod_{p}^{\mathrm{CM}}\left(f^{\mathrm{CM}}\right)=q_{a} f^{\mathrm{CM}}+F^{\mathrm{CM}}, \\
& \prod_{r}^{\mathrm{CM}}\left(F^{\mathrm{CM}}\right)=q_{a}\left(p_{1}-f^{\mathrm{CM}}\right)+\left(q_{b}+q_{c}\right) p_{2}-F^{\mathrm{CM}}, \\
& \text { s.t. }\left\{\begin{array}{l}
q_{a} f^{\mathrm{CM}}+F^{\mathrm{CM}}>\Pi_{p}^{R *} \\
q_{a}\left(p_{1}-f^{\mathrm{CM}}\right)+\left(q_{b}+q_{c}\right) p_{2}-F^{\mathrm{CM}}>\Pi_{r}^{D *} \\
p_{1}^{C M} * p_{1}^{C *}, p_{2}^{C M *}=p_{2}^{C *} .
\end{array}\right.
\end{aligned}
$$

From the constraints of (7), (8), and combination (9), it is easy to know that the total profit of the supply chain in model CM is equal to the optimal profit of the supply chain under centralized decision. When the first two constraints of (9) are satisfied, the retailer and the third-party presale platform can obtain retained profits under single presale model so that both parties have the motivation to participate in the contract; the latter two constraints can guarantee the same sales volume as that under the centralized model so as to maximize the profits of the supply chain.

Proposition 10. In this coordination model, the unit commission of the third-party presale platform $f^{C M *}=0$, and the fee that the retailer has to pay to the third-party presale platform meets the following requirement: $(\lambda / 8) \leq F^{C M *} \leq(3 \eta \lambda /(64-$ $16 \eta \lambda))$.

Proposition 10 shows that, in the coordination model, the third-party presale platform will not charge the unit commission of the platform but directly charge the transfer payment fee of the retailer, and the supply chain can still obtain the optimal profit equal to the centralized decisionmaking. At the same time, it also shows that the third-party presale platform can obtain higher sales volume by using lower retail price than by charging unit commission. Retailer and third-party presale platform can obtain additional profits. The profit earned by the third-party presale platform depends on the fixed fee paid by the retailer, which is related to the decision-making influence of the third-party presale platform in the supply chain. Therefore, the coordination strategy can coordinate the supply chain well and achieve better economic and social benefits.

\section{Numerical Analysis}

In order to more intuitively and effectively illustrate the above analysis and verify the correctness of the above analysis, this section combines with numerical examples to verify the above analysis.

5.1. Model Comparison. We can know from Propositions 6-9 that, under the premise of $\eta, \lambda \in(0,1)$, there is always an exact size relation, except for a special case: as shown in Proposition 6 , when $\eta$ and $\lambda$ are in different ranges, the presale prices under different models show different size relationships. As shown in Figure 2 , there is $p_{1}^{D *}<p_{1}^{R *}$ in Zone 1 , and $p_{1}^{R *}<p_{1}^{D *}$, in

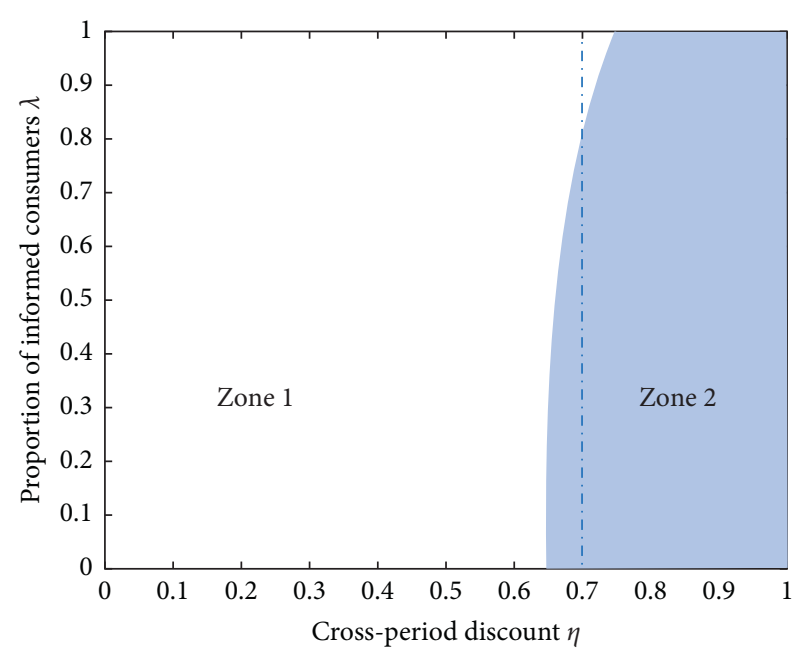

Figure 2: The size relationship between $p_{1}^{R *}$ and $p_{1}^{D *}$.

Zone 2. That is to say, the value of $\eta \in((2 / 3), 3-\sqrt{5})$ can make it representative. So, we make $\eta=0.7$ in this interval.

Let $\eta=0.7$, and the effects of the proportion of informed consumers $\lambda$ on the presale price, spot price, and profit under different decision models are compared and analyzed.

As can be seen from Figure 3, when the proportion of informed consumers is 0.7 , cross-period discount will affect sales to varying degrees. When the cross-period discount $\lambda$ increases, it will stimulate the sales volume in the presale period and reduce the sales volume in the spot-sale period. This is because the cross-period discount is directly related to the consumer utility of products purchased in the spot-sale period: the increase of cross-period discount will significantly reduce the satisfaction of consumers in the spot-sale period, so they will be more inclined to purchase in the presale period. In the presale period, the sales volume of the centralized decision-making model is the highest, and the increase rate with parameter $\lambda$ is higher than that of decentralized decision-making; in the spot-sale stage, the sale volume in the decentralized decision-making model is larger than that in the centralized decision-making model.

From Figure 4, we can see that both the presale price and the spot-sale price will be affected by the cross-period discount: the presale price will decrease with the increase of parameter $\lambda$, while the presale price in model $R$ and the spot-sale price in model $N$ are not affected by parameter $\lambda$. This is because both model $N$ and model $R$ operate in a single cycle, so the crossperiod discount will not have an impact. When $\lambda$ remains at a high level, consumers who give up buying in the presale period will bear a greater loss of psychological comfort, so consumers will be more inclined to buy in the presale period; in this case, the retailer can reduce the presale price slightly and significantly reduce the spot-sale price to achieve profit optimization. The presale and spot-sale price of centralized decision-making is always less than that of decentralized decisionmaking, and the decrease rate with the increase of parameter $\lambda$ is always greater than that of decentralized decision-making.

From Figure 5, it can be seen that the probability of informed consumers will affect the profits of model $D$, model $C$, and model $R$, which is independent of the profits of model 


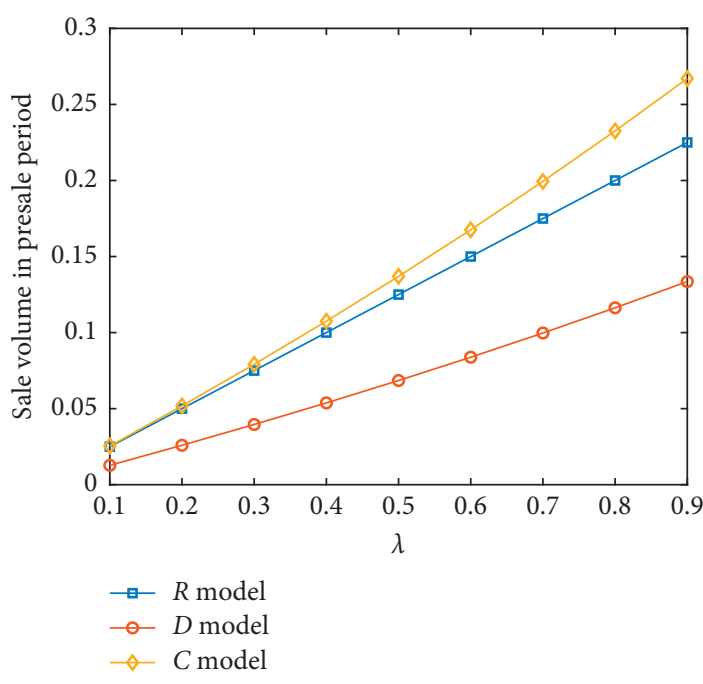

(a)

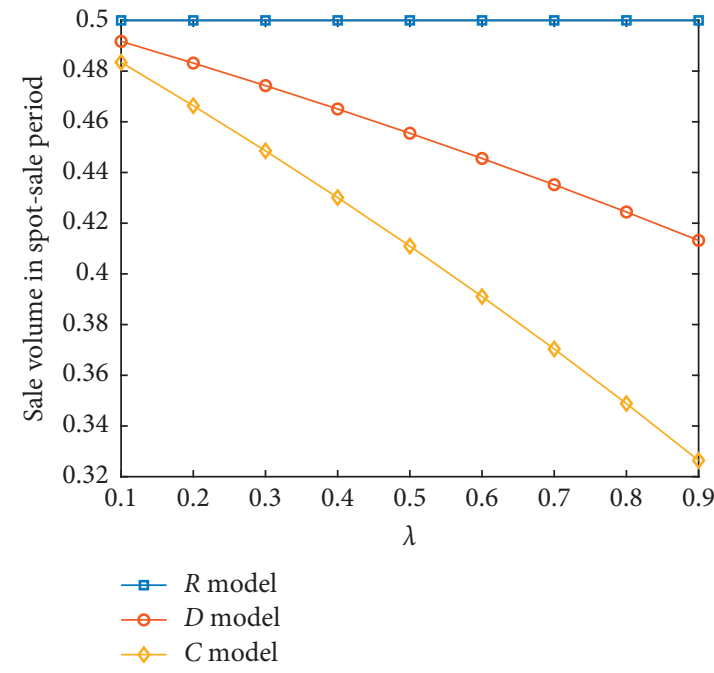

(b)

Figure 3: The influence of $\lambda$ on sales volume. (a) Sale volume in the presale period. (b) Sale volume in the spot-sale period.

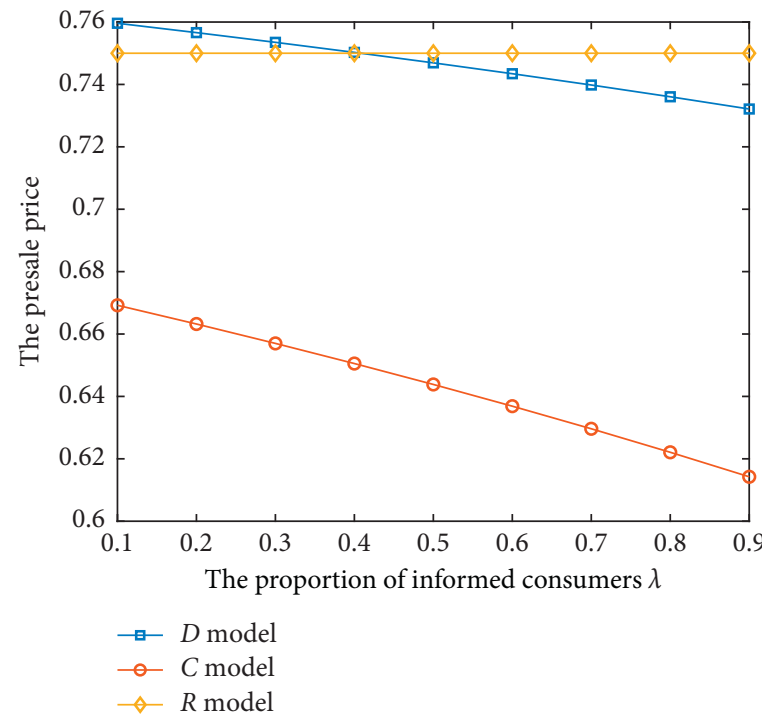

(a)

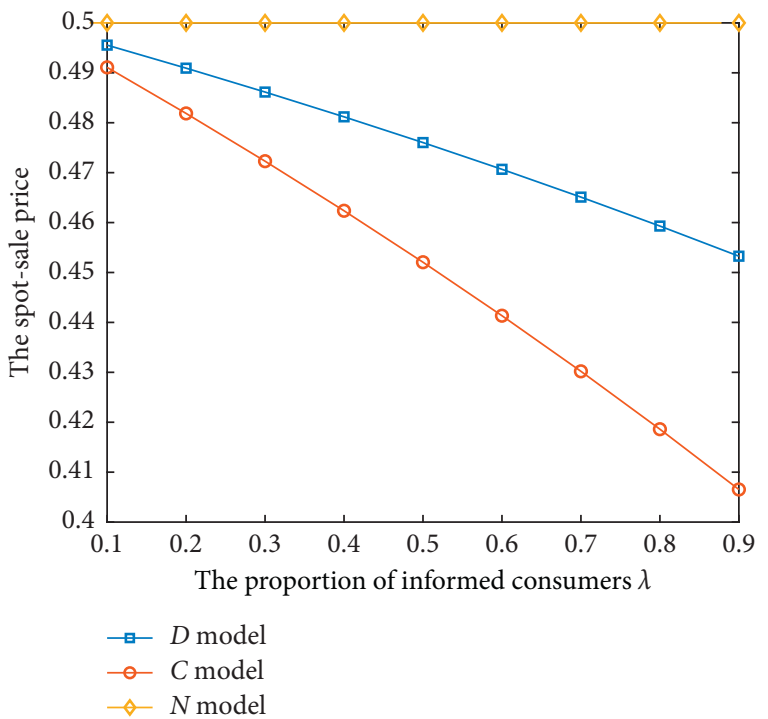

(b)

Figure 4: The effect of $\lambda$ on presale price and spot-sale price. (a) Presale price in different models. (b) Spot-sale price in different models.

$N$. In the above decision models, the profits are increased with the increase of parameter $\lambda$. The total profit of model $C$ is always the highest, and the retailer profit of model $D$ is next. This is because the centralized decision-making model has high synergy, can overcome the double marginal effect, make decisions on the difference between the presale price and the spot-sale price, obtain unit profit higher than the presale period, and achieve profit growth under the situation of increasing the probability of informed consumers. Compared with the rate of profit change of the supply chain or supply chain members in the above different models, retailer profit in model $R$ increases fastest; this is because in model $R$, the size of $\lambda$ is directly related to the sales volume in the presale period and has the greatest impact. This phenomenon shows that the retailer needs to carry out multichannel operation in order to obtain more profits and increase the sales cycle to get more profits by using the "presale and spot-sale" model.

5.2. Parameter Sensitivity Analysis. This section will analyze the impact of the cross-period discount and the proportion of informed consumers on the equilibrium price and profit of the supply chain under different decision-making situations.

From Figure 6, we can see that both centralized and decentralized decision-making have the following 


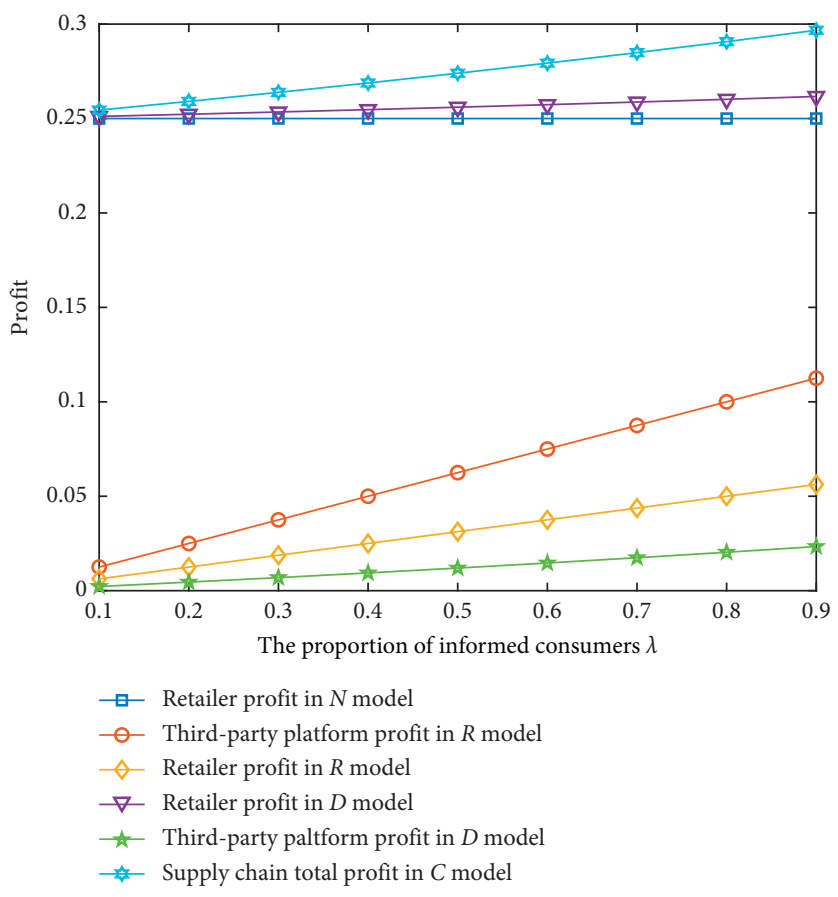

Figure 5: The effect of $\lambda$ on profits.

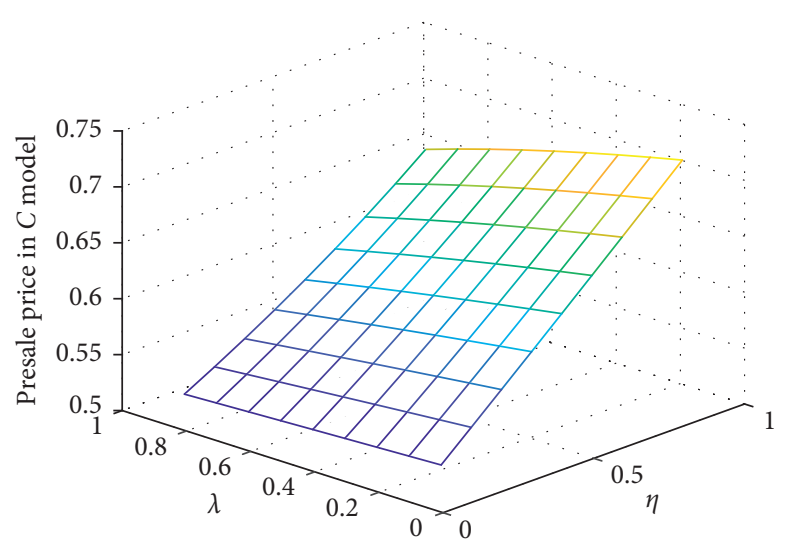

(a)

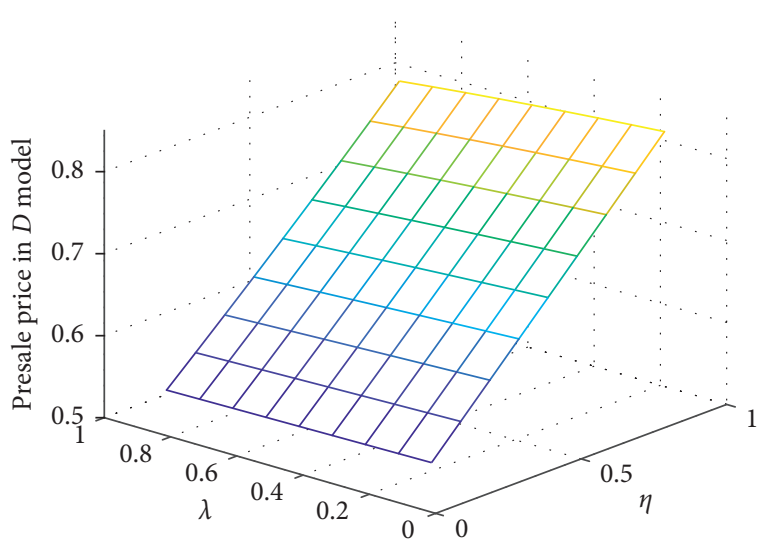

(b)

Figure 6: The effect of $\eta$ and $\lambda$ on the presale price. (a) Presale price in model C. (b) Presale price in model $D$.

characteristics: the proportion of informed consumers has little effect on the presale price, and the increase of the proportion of informed consumers can improve the presale price to some extent, but the effect is not significant. Therefore, the retailer needs to pay more attention to the impact of cross-period discount when setting prices; more recently, when ordering goods, they need to examine the preferences of consumers and the attributes of goods.

Compared with the influence of parameter $\lambda$ on prices, the cross-period discount in the spot period has significant effect on prices. By comparing Figure 6(a) and Figure 6(b), we can see that the presale price of model $D$ is higher than that of model $C$ in the same situation. This is because model $C$ aims at maximizing the overall profit of the supply chain and can set a lower price to promote sales volume so as to maximize the overall profit.

From Figure 7, it can be seen that parameters $\eta$ and $\lambda$ have an effect on both centralized and decentralized models, and the influence of the two on the spot-sale price in the centralized decision-making and decentralized decisionmaking is similar. When the parameter $\lambda$ or $\eta$ (marked as $\lambda / \eta$ below) is determined, the spot-sale price decreases with the increase of parameter $\lambda / \eta$, and the larger the parameter $\lambda / \eta$, the faster the spot-sale price decreases. When parameters $\lambda$ and $\eta$ are close to 0 , the present price has the maximum value. At this time, the situation is that the consumers in the market are almost unaware of the retailer's presale strategy, and the retailer's supply is very sufficient to meet the market 


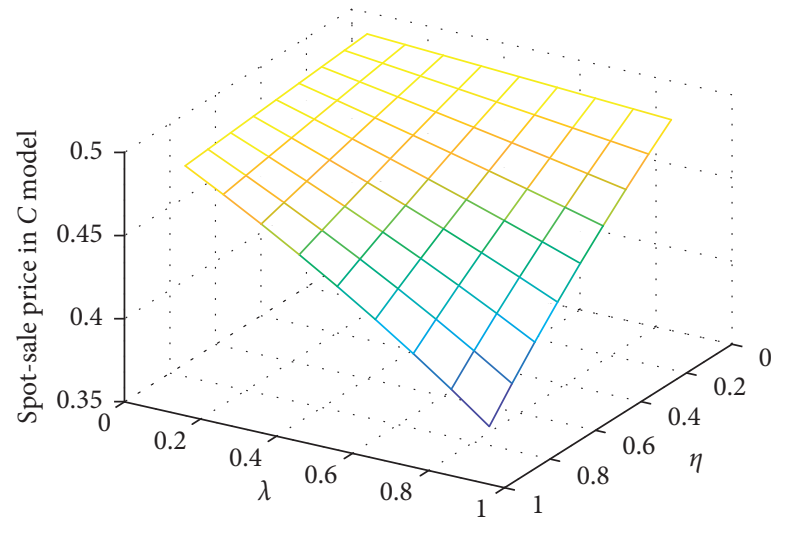

(a)

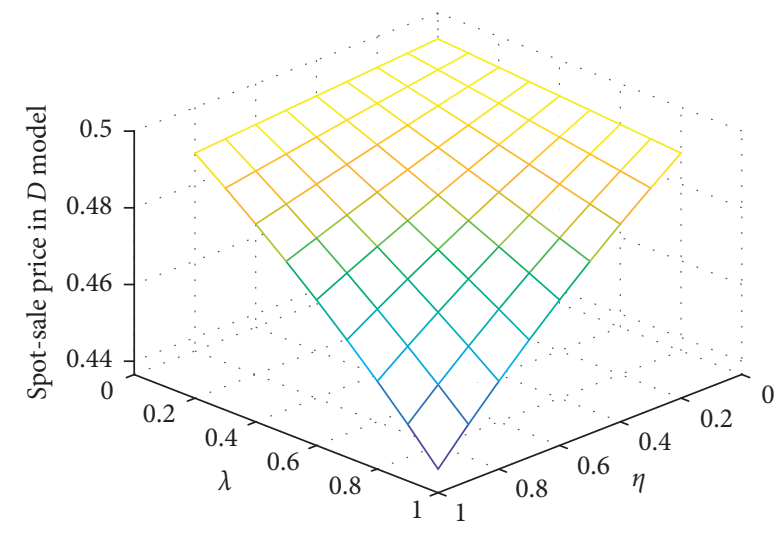

(b)

Figure 7: The effect of $\eta$ and $\lambda$ on the spot-sale price. (a) Spot-sale price in model $C$ (b) Spot-sale price in model $D$.

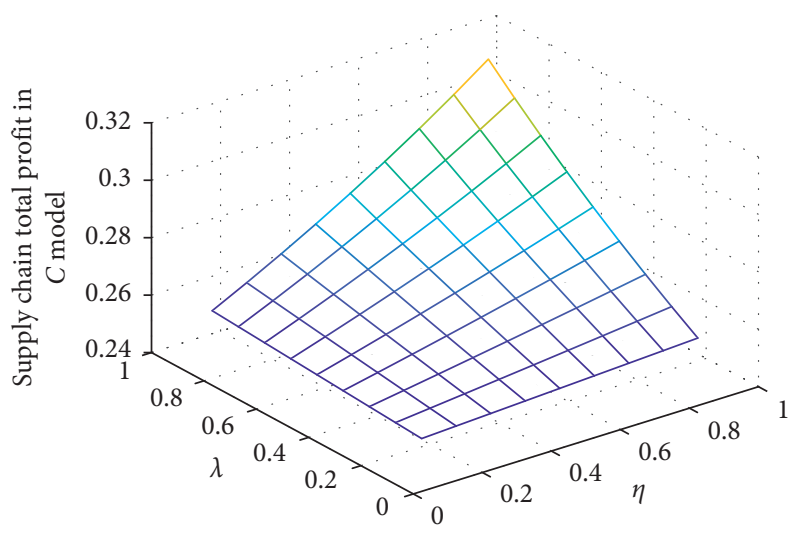

(a)

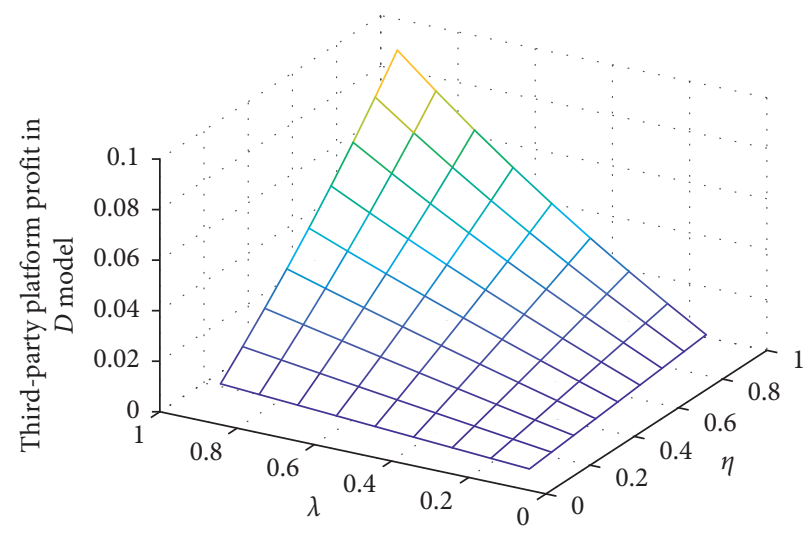

(b)

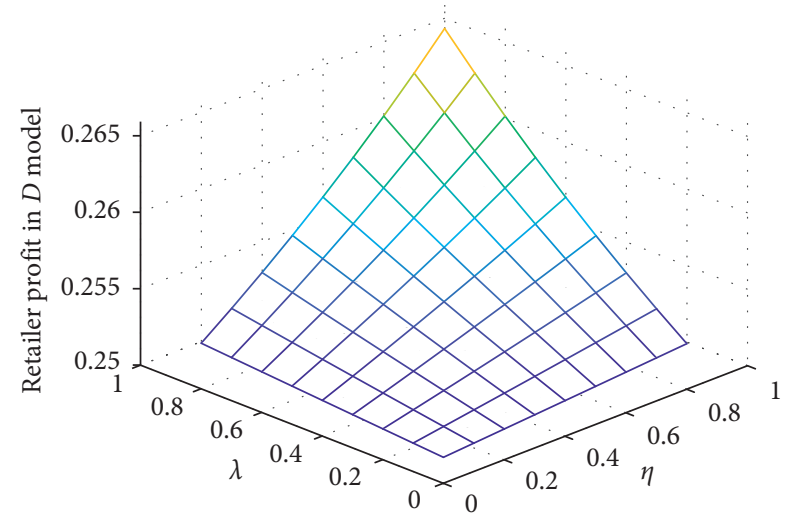

(c)

Figure 8: Impacts of $\eta$ and $\lambda$ on the profits of the supply chain and its members. (a) Total supply chain profit in model C. (b) Third-party presale platform's profit in model $D$. (c) Retailer's profit in model $D$.

demand. This situation is similar to the spot model ( $N$ model), so the present price is close to the optimal retail price of model $N$.

As can be seen from Figure 8, the parameters $\eta$ and $\lambda$ can affect the profits of the supply chain and supply chain members in different decision models, and the parameters $\eta$ and $\lambda$ under the same decision model have similar effects on the same subject profit. When any one of $\eta, \lambda$ increases, the profit of the third-party presale platform of the decentralized decision will increase, and the maximum profit will be obtained when $\eta$ and $\lambda$ take the maximum value. Compared with Figures 8(b) and 8(c), we can see that although the third-party presale platform is the leader in model $D$, the profit of the third-party presale platform in model $D$ is 
always smaller than that of the retailer. This is because the profit of the retailer comes from the presale period and the spot-sale period, while the revenue of the third-party presale platform comes only from the platform commission collected during the presale process.

\section{Concluding Remarks}

This paper constructs a supply chain structure consisting of a retailer and a third-party presale platform. Using the Stackelberg game method, four supply chain decision models are constructed including the presale model, spotsale model, decentralized decision-making model, and centralized decision-making model under the "presale and spot-sale" model. The optimums of these four models are compared and analyzed, and the influence of the proportion of informed consumers and the cross-period discount on supply chain decision-making is further analyzed. We can obtain the following results:

(1) Compared with the single presale model and the single spot-sale model, the "presale and spot-sale" model is conducive to improving the profit of the supply chain. In the "presale and spot-sale" model, centralized decision-making is better than decentralized decision-making in all respects, which shows that centralized decision-making has lower presale price and spot price, higher overall sales volume, and higher total profit of the supply chain. In the retail supply chain, the retailers need to expand their sales channels properly to avoid the disadvantage of the single channel.

(2) The exogenous variables such as the proportion of informed consumers and the cross-period discount in the spot-sale period also have impacts on the decision-making and profits of the supply chain. Any increase in proportion of informed consumers or cross-period discount will increase profits. So, when the retailer sets prices, she needs to research the market environment to meet the market demand.

(3) In the coordination strategy of the supply chain, the third-party presale platform will be more inclined to charge fixed platform fee from the retailer, and the fixed platform usage fee is related to its own decision-making influence in the supply chain, and the coordination contract can coordinate the operation of the supply chain. Supply chain members should seek cooperation within the possible scope, coordinate cooperation from the perspective of the whole supply chain, and avoid fighting alone.

The main contributions of this paper are as follows: firstly, we make up a consumption mix of presale and spot-sale for consumers to choose. The influence of consumers' preferences on supply chain decision-making under the situation of spotsale and presale is analyzed. Secondly, a coordination contract is formed to coordinate the decentralized decision supply chain under the mode of "presale and sale," and the coordinated operation among supply chain members is realized.
There are still some shortcomings in this paper. Firstly, the reservation price of consumers is considered as a uniform distribution. In fact, it is more realistic to describe the retailer's retail price distribution by normal distribution. Secondly, the proportion of informed consumers is related to the popularity of the third-party presale platform or retailer's advertising investment. In the future, we can analyze the presale and spot-sale strategy from the perspective of the impact of advertising investment on the proportion of informed consumers.

\section{Appendix}

\section{A. Proof of Proposition 1}

Proof. The conditions for informed consumers to choose to buy products in the spot-sale period are $u_{b}>u_{a}$ and $u_{b}>0$, that is, $\left(v-p_{2}\right)(1-\eta)>v-p_{1},\left(v-p_{2}\right)(1-\eta) \geq 0$. The range of $v$ is $p_{2} \leq v<\left(\left(p_{1}-p_{2}+\eta p_{2}\right) / \eta\right)$. If and only if $p_{2}<\left(p_{1}-p_{2}+\eta p_{2}\right) / \eta$, the inequality has a solution, and $p_{1}>p_{2}$ is obtained. Therefore, on the premise of $p_{1}>p_{2}$, the consumers whose reservation price meets $p_{2} \leq v<\left(\left(p_{1}-p_{2}+\eta p_{2}\right) / \eta\right)$ will purchase the products in the spot-sale period.

Informed consumers choose to buy products in the presale period under the condition of $u_{a} \geq u_{b}$ and $u_{a} \geq 0$, i.e., $v-p_{1} \geq\left(v-p_{2}\right)(1-\eta)$ and $v-p_{1} \geq 0$. We obtain $v \geq \max \left\{\left(p_{1}-p_{2}+\eta p_{2}\right) / \eta, p_{1}\right\}$. This paper is discussed in the case that both presale products and spot-sale products have markets. Consumers' purchase in the spot-sale period on the premise is that $p_{1}>p_{2}$. Then, it is easy to know that $\max \left\{\left(\left(p_{1}-p_{2}+\eta p_{2}\right) / \eta\right), p_{1}\right\}=\left(p_{1}-p_{2}+\eta p_{2}\right) / \eta$ because $v$ is distributed on $[0,1]$ so that $\left(\left(p_{1}-p_{2}+\eta p_{2}\right) / \eta\right) \leq v \leq 1$.

The purchase decision of uninformed consumers is relatively simple. Uninformed consumers do not participate in the presale process but only make decisions at the stage of sale. Consumers will buy when their utility is not less than zero, that is, $v-p_{2} \geq 0$, and because $v$ is distributed in $[0,1]$, there is $p_{2} \leq v \leq 1$. The proof is complete.

\section{B. Proof of Proposition 3}

Proof. The decision-making sequence in model $R$ conforms to Stackelberg game and is solved by the inverse induction method. Because the retailer is a follower in the supply chain, it needs to solve first. By substituting $q_{a}=\left(1-p_{1}\right) \lambda$ into (3), we can get $\prod_{r}^{R}\left(p_{1}\right)=\lambda\left(1-p_{1}\right)\left(p_{1}-f\right)$, and intelligible (3) has a maximum value. According to $\partial \Pi_{r}^{R} / \partial p_{1}=0$, the reaction function $p_{1}=((1+f) / 2)$ of $p_{1}$ with respect to $f$ can be obtained. When (4) is taken as the maximum value, the value $f_{1}^{R *}=1 / 2$ and $p_{1}^{R *}=3 / 4$.

\section{Proof of Proposition 5}

Proof. The Hessian matrix of $\Pi_{T}^{C}$ for $p_{1}$ and $p_{2}$ in (9) is $\left[\begin{array}{cc}-(2 \lambda / \eta) & ((2 / \eta)-1) \lambda \\ ((2 / \eta)-1) \lambda & -2((1+(1-\eta) \lambda) / \eta)\end{array}\right]$. The matrix is negative definite, so (9) has a maximum value. According to 
$\partial \Pi_{T}^{C} / \partial p_{1}=0$ and $\partial \Pi_{T}^{C} / \partial p_{2}=0$, the simultaneous equation $p_{1}=1+((2-\eta) /(-4+\eta \lambda)), p_{2}=1+(2 /(-4+\eta \lambda))$ is obtained. The total profit of the supply chain can be calculated as $\Pi_{T}^{C *}=1 /(4-\eta \lambda)$.

\section{Proof of Proposition 6}

Proof. Comparing the results of Table 2 , we can get $p_{1}^{D *}-$ $p_{1}^{C *}=\eta(2+(1-\eta) \lambda) / 4(4-\eta \lambda)$ and $p_{1}^{R *}-p_{1}^{C *}=(4-4 \eta+$ $\lambda \eta) /(16-4 \eta \lambda)$. It is easy to see that the denominator and molecule of both formulas are greater than zero, so we can get $p_{1}^{D *}-p_{1}^{C *}>0$ and $p_{1}^{R *}-p_{1}^{C *}>0$. So, we need to compare the relationship between $p_{1}^{D *}$ and $p_{1}^{R *}$.

By calculating the spot-sale volume $p_{1}^{R *}-p_{1}^{D *}=\left(4-6 \eta+\eta^{2} \lambda\right) /(16-4 \eta \lambda)$, it is easy to know that the denominator $16-4 \eta \lambda>0$, and we need to judge whether the molecule $4-6 \eta+\eta^{2} \lambda$ is positive or negative. After simple mathematical calculation, we can get the following formula:

$$
\begin{cases}4-6 \eta+\eta^{2} \lambda \geq 0, & \lambda \geq-\frac{4-6 \eta}{\eta^{2}} \\ 4-6 \eta+\eta^{2} \lambda<0, & \lambda<-\frac{4-6 \eta}{\eta^{2}}\end{cases}
$$

We record $-\left((4-6 \eta) / \eta^{2}\right)$ as $Q$, and then, we get $\partial Q / \partial \eta=$ $\left((8-6 \eta) / \eta^{3}\right)>0$ by partial derivation. Then, $Q$ is positively correlated with $\eta$.

$$
\begin{cases}Q \leq 0, & 0<\eta \leq \frac{2}{3}, \\ 0 \leq Q \leq 1, & \frac{2}{3} \leq \eta \leq 3-\sqrt{5}, \\ Q>1, & 3-\sqrt{5}<\eta<1 .\end{cases}
$$

By summarizing (D.1) and (D.2), we can get (D.3):

$$
\left\{\left\{\begin{array}{l}
4-6 \eta+\eta^{2} \lambda \geq 0,(\eta, \lambda) \in\left\{3-\sqrt{5}<\eta<1, \text { or }\left[\frac{2}{3}<\eta<3-\sqrt{5} \text { and } \frac{2(3 \eta-2)}{\eta^{2}}<\lambda<1\right]\right\} \\
4-6 \eta+\eta^{2} \lambda<0, \quad(\eta, \lambda) \in\left\{0<\eta<\frac{2}{3}, \text { or }\left[\frac{2}{3}<\eta<3-\sqrt{5} \text { and } 0<\lambda<\frac{2(3 \eta-2)}{\eta^{2}}\right]\right\}
\end{array}\right\} .\right.
$$

By taking formula (D.3) into $p_{1}^{R *}-p_{1}^{D *}=\left(4-6 \eta+\eta^{2} \lambda\right) /(16-4 \eta \lambda)$, we can know the size relationship of $p_{1}^{R *}$ and $p_{1}^{D *}$.

Here, we prove the relationship between $p_{2}^{N *}, p_{2}^{D *}$, and $p_{2}^{C *}$ : we can get $p_{2}^{N *}-p_{2}^{C *}=(\eta \lambda /(8-2 \eta \lambda))>0$; $p_{2}^{N *}-p_{2}^{D *}=(\lambda \eta /(16-4 \eta \lambda))>0 ; \quad$ and $p_{2}^{D *}-p_{2}^{C *}=$ $(\lambda \eta /(16-4 \eta \lambda))>0$. So, the spot-sale prices are related as $p_{2}^{C *}<p_{2}^{D *}<p_{1}^{N *}$.

\section{E. Proof of Proposition 7}

Proof. Comparing the results of Table 2, we can get $q_{a}^{C *}=2 q_{a}^{D *}>0$. By calculating the difference between presale model and decentralized decision-making model, we can get $q_{a}^{R *}-q_{a}^{D *}=\lambda(2-\eta \lambda) / 4(4-\eta \lambda)>0$, thus the relationship between $q_{a}^{C *}, q_{a}^{D *}, q_{a}^{R *}$ is $q_{a}^{C *}>q_{a}^{R *}>q_{a}^{D *}$.

By calculating the spot-sales volume, $\left(q_{b}^{D *}+q_{c}^{D *}\right)-\left(q_{b}^{C *}+q_{c}^{C *}\right)=(\lambda(2-\eta \lambda) / 4(4-\eta \lambda))>0$, so the spot-sale volume of the centralized decision model is always lower than that of the decentralized decision model, and we need to compare the sales volume of model $C$, model $D$, and model $N$. From $q_{c}^{N *}-\left(q_{b}^{D *}+q_{c}^{D *}\right)=$ $((2-\eta) \lambda / 4(4-\eta \lambda))>0$, we have $q_{2}^{N *}>q_{2}^{D *}$, so, the relationship between $q_{2}^{C *}, q_{2}^{D *}, q_{2}^{N *}$ is $q_{2}^{N *}>q_{2}^{D *}>q_{2}^{C *}$.

\section{F. Proof of Proposition 8}

Proof. After simple mathematical calculation, we can easily get $\Pi_{r}^{D *}-\Pi_{r}^{N *}=(\eta \lambda /(16(4-\eta \lambda)))>0 \quad$ and $\Pi_{p}^{R *}-\Pi_{p}^{D *}=((4-\eta-\eta \lambda) \lambda / 8(4-\eta \lambda))>0$, and then, we can get the conclusion of $\Pi_{r}^{D *}>\Pi_{r}^{N *}$ and $\Pi_{p}^{R *}>\Pi_{p}^{D *}$. Next, we start to prove $\Pi_{r}^{D *}>\Pi_{r}^{R *}$ as follows:

$$
\Pi_{r}^{D *}-\Pi_{r}^{R *}=\frac{\eta\left(\lambda^{2}-3 \lambda\right)+16-4 \lambda}{16(4-\eta \lambda)} .
$$

Because of $\lambda, \eta \in(0,1)$, we can easily find that the denominator of (F.1) is positive. Next, we will discuss the positive and negative properties of molecules in the following two cases:

$$
\begin{array}{lll}
\text { (1) When } & \eta \leq(16-4 \lambda) /\left(3 \lambda-\lambda^{2}\right), & \eta\left(\lambda^{2}-\lambda\right)+ \\
16-4 \lambda \geq 0 & \\
\text { (2) When } & \eta>(16-4 \lambda) /\left(3 \lambda-\lambda^{2}\right), & \eta\left(\lambda^{2}-\lambda\right)+ \\
16-4 \lambda<0 & &
\end{array}
$$

We mark $(16-4 \lambda) /\left(3 \lambda-\lambda^{2}\right)$ as $K$ and derive $K$ to get $(\partial K / \partial \lambda)=-\left(4(6-\lambda)(2-\lambda) /(3-\lambda)^{2} \lambda^{2}\right)<0$. Then, $K$ decreases with the increase of $\lambda$. In the range of $\lambda \in(0,1)$, the minimum value of $K$ is $K_{\min }=\lim _{\lambda \longrightarrow 1}\left(16-4 \lambda / 3 \lambda-\lambda^{2}\right)=6$. Because of $\eta \in(0,1)$, case (2) will not be satisfied, and case (1) 
will always be satisfied. It can be concluded that the molecule of (F.1) is positive, so there is $\Pi_{r}^{D *}>\Pi_{r}^{R *}$.

\section{G. Proof of Proposition 9}

Proof. Because of $\Pi_{T}^{*}=\Pi_{r}^{*}+\Pi_{p}^{*}$, which can be calculated from Table $2, \Pi_{T}^{N *}=1 / 4, \Pi_{T}^{D *}=(16-\lambda \eta) /(64-16 \lambda \eta)$, $\Pi_{T}^{C *}=1 /(1-\lambda \eta), \Pi_{T}^{R *}=3 \lambda / 16 . \quad \Pi_{T}^{D *}-\Pi_{T}^{N *}=3 \lambda \eta /(64-$ $16 \lambda \eta)$, and both the denominator and the molecule of this are greater than $0, \Pi_{T}^{D *}-\Pi_{T}^{N *}>0 . \quad \Pi_{T}^{C *}-\Pi_{T}^{D *}=$ $\lambda \eta /(64-16 \lambda \eta)$, similar to the previous one, you can get $\Pi_{T}^{C *}-\Pi_{T}^{D *}>0$. So, we can get $\Pi_{T}^{C *}>\Pi_{T}^{D *}>\Pi_{T}^{N *}$. And because $\lambda \in[0,1]$, the maximum value of $\Pi_{T}^{R *}=3 \lambda / 16$ is $3 / 16$, which is still less than $\Pi_{T}^{N *}$, so we can get $\Pi_{T}^{R *}<\Pi_{T}^{N *}$.

In summary, $\Pi_{T}^{C *}>\Pi_{T}^{D *}>\Pi_{T}^{N *}>\Pi_{T}^{R *}$ can be obtained, and the proof is complete.

\section{H. Proof of Proposition 10}

Proof. According to the solving process of model $D$, the reaction functions of $p_{1}$ and $p_{2}$ with respect to $f$ are $p_{1}(f)=$ $(-2+\eta(-1+\lambda)+f(-2+(-1+\eta) \lambda)) /(-4+\eta \lambda) \quad$ and $p_{2}(f)=(2+f \lambda-\eta \lambda) /(4-\eta \lambda)$, respectively. The optimal solution of $f^{C M *}=0$ can be easily obtained from the constraints $p_{1}^{C M *}=p_{1}^{C *}, p_{2}^{C M *}=p_{2}^{C *}$. Then, the profits of the retailer and the third-party presale platform can be calculated as $\Pi_{p}^{\mathrm{CM}}=F^{\mathrm{CM}}$ and $\Pi_{r}^{\mathrm{CM}}=(1 /(4-\eta \lambda))-F^{\mathrm{CM}}$, respectively. Because the profits of the retailer and the thirdparty presale platform after coordination are not less than the retained profits, $(\lambda / 8)<F^{C M *}<(3 \eta \lambda /(64-16 \eta \lambda))$ can be obtained by $F^{\mathrm{CM}}>\Pi_{p}^{D *},(1 /(4-\eta \lambda))-F^{\mathrm{CM}}>\Pi_{r}^{D *}$. The proof is complete.

\section{Data Availability}

The data used to support the findings of this paper are included in the main text and appendix part of the article. The Mathematica code file has been sent to the publisher of the article.

\section{Conflicts of Interest}

The authors declare that they have no conflicts of interest.

\section{Acknowledgments}

This research was supported by the National Natural Science Foundation of China (71301126), Hubei Province University Philosophy and Social Science Research Major Project (provincial social science fund prefunded project) (19ZD036), and Hubei Provincial Education Department Philosophy and Social Science Research Key Project (19 D035).

\section{References}

[1] H. He, X. H. Gan, and K. F. Yuan, "Entry of online presale of fresh produce: a competitive analysis," European Journal of Operational Research, vol. 272, no. 1, pp. 339-351, 2018.
[2] W. Mei, L. Du, B. Niu, J. Wang, and J. Feng, "The effects of an undisclosed regular price and a positive leadtime in a presale mechanism," European Journal of Operational Research, vol. 250, no. 3, pp. 1013-1025, 2016.

[3] L. Guo and J. M. Villas-Boas, "Consumer stockpiling and price competition in differentiated markets," Journal of Economics \& Management Strategy, vol. 16, no. 4, pp. 827858, 2007.

[4] O. Jadidi, S. Taghipour, and S. Zolfaghari, "A two-price policy for a newsvendor product supply chain with time and price sensitive demand," European Journal of Operational Research, vol. 253, no. 1, pp. 132-143, 2016.

[5] W. S. Lim and C. S. Tang, "Advance selling in the presence of speculators and forward-looking consumers," Production and Operations Management, vol. 22, no. 3, pp. 571-587, 2013.

[6] A. Prasad, K. E. Stecke, and X. Zhao, "Advance selling by a newsvendor retailer," Production and Operations Management, vol. 20, no. 1, pp. 129-142, 2011.

[7] H. Zhang, Y. Liu, and J. Huang, "Supply chain coordination contracts under double sided disruptions simultaneously," Mathematical Problems in Engineering, vol. 2015, Article ID 812043, 9 pages, 2015.

[8] M. Johari and S.-M. Hosseini-Motlagh, "Coordination of social welfare, collecting, recycling and pricing decisions in a competitive sustainable closed-loop supply chain: a case for lead-acid battery," Annals of Operations Research, vol. 503, no. 9, pp. 606-634, 2019.

[9] S.-M. Hosseini-Motlagh, M. Nouri-Harzvili, T.-M. Choi, and S. Ebrahimi, "Reverse supply chain systems optimization with dual channel and demand disruptions: sustainability, CSR investment and pricing coordination," Information Sciences, vol. 503, pp. 606-634, 2019.

[10] A. Arya, B. Mittendorf, and D. E. M. Sappington, "The bright side of supplier encroachment," Marketing Science, vol. 26, no. 5, pp. 651-659, 2007.

[11] M. E. Ferguson and L. B. Toktay, "The effect of competition on recovery strategies," Production \& Operations Management, vol. 15, no. 3, pp. 351-368, 2010.

[12] H. José, A. Felipe, and B. Michael, "Agent interactions and the response of supply chains to pricing and incentives," Economics of Transportation, vol. 4, no. 3, pp. 147-155, 2015.

[13] C. Wang, W. Wang, and R. Huang, "Supply chain enterprise operations and government carbon tax decisions considering carbon emissions," Journal of Cleaner Production, vol. 152, pp. 271-280, 2017.

[14] M. Sarkar and Y. Hae Lee, "Optimum pricing strategy for complementary products with reservation price in a supply chain model," Journal of Industrial \& Management Optimization, vol. 13, no. 3, pp. 1553-1586, 2017.

[15] R. Batarfi, M. Y. Jaber, and C. H. Glock, "Pricing and inventory decisions in a dual-channel supply chain with learning and forgetting," Computers \& Industrial Engineering, vol. 136, pp. 397-420, 2019.

[16] A. RanjanVoigt and J. K. Jha, "Pricing and coordination strategies of a dual-channel supply chain considering green quality and sales effort," Journal of Cleaner Production, vol. 218, pp. 409-424, 2019.

[17] K. Conrad, "Price competition and product differentiation when consumers care for the environment," Environmental \& Resource Economics, vol. 31, no. 1, pp. 1-19, 2005.

[18] G. Ferrer and J. M. Swaminathan, "Managing new and differentiated remanufactured products," European Journal of Operational Research, vol. 203, no. 2, pp. 370-379, 2010. 
[19] K. Chitra, "In search of the green consumers: a perceptual study," Journal of Services Research, vol. 7, no. 1, pp. 173-191, 2007.

[20] A. Atasu, M. Sarvary, and L. N. Van Wassenhove, "Remanufacturing as a marketing strategy," Management Science, vol. 54, no. 10, pp. 1731-1746, 2008.

[21] J. V. D. R. Guide and J. Y. Li, "The potential for cannibalization of new products sales by remanufactured products," Decision Sciences, vol. 41, no. 3, pp. 547-572, 2010.

[22] C. Li and F. Zhang, "Advance demand information, price discrimination, and preorder strategies," Manufacturing \& Service Operations Management, vol. 15, no. 1, pp. 57-71, 2013.

[23] S.-S. Gan, I. N. Pujawan, Suparno, and B. Basuki, "Pricing decision for new and remanufactured product in a closedloop supply chain with separate sales-channel," International Journal of Production Economics, vol. 190, pp. 120-132, 2017.

[24] J. D. Abbey, R. Kleber, G. C. Souza, and G. Voigt, "The role of perceived quality risk in pricing remanufactured products," Production and Operations Management, vol. 26, no. 1, pp. 100-115, 2017.

[25] T. S. Genc and P. De Giovanni, "Optimal return and rebate mechanism in a closed-loop supply chain game," European Journal of Operational Research, vol. 269, no. 2, pp. 61-681, 2018.

[26] S.-H. Cho and C. S. Tang, "Advance selling in a supply chain under uncertain supply and demand," Manufacturing \& Service Operations Management, vol. 15, no. 2, pp. 305-319, 2013.

[27] R. Dekker, M. Fleischmann, K. Inderfurth et al., Reverse Logistics: Quantitative Models for Closed-Loop Supply Chains, Springer, Berlin, Germany, 2004.

[28] R. C. Savaskan and L. V. Wassenhove, "Reverse channel design: the case of competing retailers," Management Science, vol. 52 , no. 5 , pp. $1-14,2006$.

[29] R. C. Savaskan, S. Bhattacharya, and L. N. Van Wassenhove, "Closed-loop supply Chain models with product remanufacturing," Management Science, vol. 50, no. 2, pp. 239-252, 2004.

[30] Q. Liu and D. Zhang, "Dynamic pricing competition with strategic customers under vertical product differentiation," Management Science, vol. 59, no. 1, pp. 84-101, 2013. 